\title{
Oral bismuth for chronic intractable diarrheal conditions?
}

This article was published in the following Dove Press journal:

Clinical and Experimental Gastroenterology

12 March 2013

Number of times this article has been viewed

\section{Sony S Thazhath \\ Mazhar Haque \\ Timothy H Florin \\ University of Queensland and Mater Adult Hospital, South Brisbane, QLD, Australia}

Correspondence: Timothy H Florin University of Queensland and Mater Adult Hospital, Head IBD Team Mater Medical Research Institute, South Brisbane, QLD 4I0I, Australia

Tel +6I 731638906

Fax +6I 731631548

Email t.florin@uq.edu.au
Objective: Bismuth has antidiarrheal, antibacterial, and anti-inflammatory properties. We report our single-center experience with oral colloidal bismuth subcitrate (CBS) treatment for patients with chronic intractable diarrhea.

Method: We interrogated our web-based Inflammatory Bowel Disease Clinical and Research database to ascertain clinical details on all patients in our tertiary hospital gastroenterology service treated with CBS between 2000 and 2010. Treatment responses were based on prospective scoring of daily number of liquid stools. Responses were recorded prior to commencement of CBS and at follow-up visits over 12 months.

Results: Thirty-one patients, mean age 47 years (range 17-79 years) and a mean duration of diarrhea of 22 weeks (range 6-104 weeks), were prescribed CBS at doses ranging from $120 \mathrm{mg}$ to $480 \mathrm{mg}$ /day for $\geq 1$ month. Of these, 23 patients (74\%) had an initial clinical response and $12(39 \%)$ who continued with this treatment had a sustained clinical response at 1 year. Twelve patients with pouchitis and four patients with indeterminate colitis had initial responses of $92 \%$ and $75 \%$, respectively, and sustained responses of $50 \%$ and $75 \%$, respectively. Ulcerative colitis patients $(n=5)$ responded poorly with respect to both initial and sustained responses. Three patients with microscopic colitis showed encouraging initial response of $100 \%$ but did not have any sustained benefit. Three of four patients with diarrhea-predominant irritable bowel syndrome (dIBS) had an initial response and two (50\%) had good sustained responses. There were no serious adverse events. One patient stopped therapy because of nausea.

Conclusion: This is the largest report of oral bismuth treatment in chronic intractable diarrhea. CBS is cheap and appears to have the potential to be effective for ameliorating diarrheal symptoms in indeterminate colitis, pouchitis, and dIBS. An appropriately powered, blinded, randomized, controlled study appears warranted to establish the position of oral bismuth in routine practice.

Keywords: oral bismuth, colloidal bismuth subcitrate, diarrhea, inflammatory bowel disease

Intractable diarrheal symptoms that are often associated with inflammatory bowel disease (IBD) and diarrheal irritable bowel syndrome (dIBS), significantly affect the quality of life of patients and can be a challenging management problem. IBD per se is treated with aminosalicylates, corticosteroids, thiopurine, or other immunosuppressive medications, either by themselves or in combinations or with surgery. Despite treatment, approximately $20 \%-30 \%$ of patients fail to achieve complete remission either because of insufficient response or unacceptable side effects. ${ }^{1,2}$ Attempts at symptomatic management of diarrhea with standard antidiarrheal treatments are not always successful. In such situations there is a dearth of alternative options. 
One of the more unusual therapies reported in older literature involves arsenical compounds. Encouraging results with $\operatorname{acetarsol}^{\mathrm{TM}}$ ([3-acetamido-4-hydroxyphenyl] arsonic acid) enemas were demonstrated in a double-blind controlled trial comparing it with a corticosteroid suppository for inducing remission in ulcerative proctitis. ${ }^{3}$ Notwithstanding, it is rarely used due to its potential for toxicity. ${ }^{4}$

Being in the same group in the periodic table, bismuth shares many chemical properties with arsenic. Oral bismuth has been used effectively for prophylaxis and treatment of traveler's diarrhea ${ }^{5}$ and for treatment of Helicobacter pylori. ${ }^{6}$

Inspired by the clinical trial literature on acetarsol in colitis and chewable oral bismuth preparations for peptic ulcer disease and travelers' diarrhea, TF in our gastroenterology service has been prescribing oral bismuth for patients with intractable diarrhea since 2000 . We report on our experience with oral colloidal bismuth subcitrate (CBS) in a consecutive series of 31 patients suffering from various chronic diarrheal conditions, including colitis, pouchitis, and dIBS, who were intolerant or unresponsive to conventional treatments.

\section{Patients and methods}

All patients with chronic diarrhea in our clinic are entered on our web-based Inflammatory Bowel Disease Clinical and Research Database (Figure 1). While primarily designed to follow patients with IBD, this database is also used to follow all patients with other defined diarrheal conditions, including microscopic colitides, celiac disease, lactase deficiency, and some pancreatic disorders. Clinical assessment and medical and surgical treatment data are updated during clinic visits.

The database was interrogated for all patients treated with CBS, and corresponding medical chart records were reviewed to confirm details of the patients treated with CBS between January 1, 2000 and December 31, 2010. The patients treated with CBS had either mild- to moderate-severity colitis, pouchitis, or chronic diarrheal conditions not responding to standard medical treatments (Table 1) but not requiring mandated surgery for the condition. None of the patients had celiac disease or lactose intolerance.

Diarrhea was scored prospectively using a clinical assessment module primarily designed to score clinical severity of Crohn's disease or colitis (Figure 2). Intractable diarrhea was defined by $\geq 4$ liquid stools per day and not responsive to primary therapy for the disease or loperamide or other interventions (Table 1). No patient who received oral CBS between 2000 and 2010 was excluded from the study. All patients were routinely warned about the possibility of passing dark stools with the use of bismuth. All patients were asked to take CBS daily for a minimum of 4 weeks. The dosing schedule was $120 \mathrm{mg}$ twice daily for 2 weeks. If patients had no response, then they were

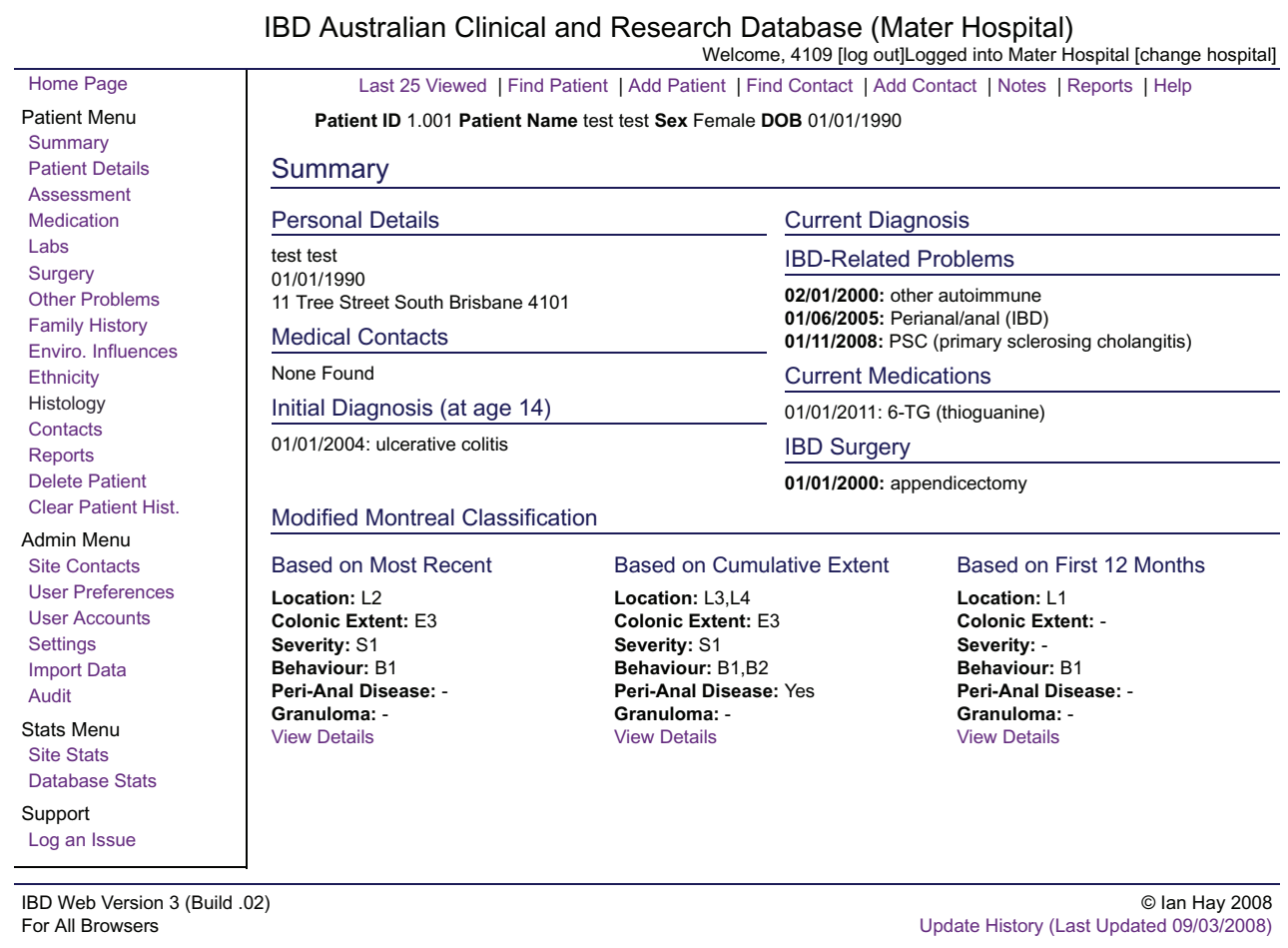

Figure I Screen shot of our web-based Inflammatory Bowel Disease (IBD) Clinical and Research Database showing the summary page for a "test" patient. 
Table I Clinical characteristics of patients and responses to oral colloidal bismuth subcitrate

\begin{tabular}{|c|c|c|c|c|c|c|c|c|c|}
\hline \multirow[t]{2}{*}{ Diagnosis } & \multirow[t]{2}{*}{$\begin{array}{l}\text { Number of patients } \\
\text { at time }=0\end{array}$} & \multirow[t]{2}{*}{$\begin{array}{l}\text { Median duration } \\
\text { of diarrhea } \\
\text { (range) weeks }\end{array}$} & \multirow[t]{2}{*}{$\begin{array}{l}\text { Prior } \\
\text { treatments }\end{array}$} & \multicolumn{3}{|c|}{$\begin{array}{l}\text { Response at } \\
\text { I month }\end{array}$} & \multicolumn{3}{|c|}{$\begin{array}{l}\text { Response at } \\
\text { I } 2 \text { months: } \\
\text { only patients } \\
\text { on bismuth } \\
\geq 4 \text { weeks } \\
\end{array}$} \\
\hline & & & & ++ & + & - & ++ & + & - \\
\hline Chronic pouchitis & 12 & $15(6-78)$ & $\begin{array}{l}\text { Metronidazole, } \\
\text { steroid, azathioprine, } \\
\text { infliximab, } \\
\text { 5-aminosalicylates }\end{array}$ & 7 & 4 & 1 & 4 & 2 & 5 \\
\hline Ulcerative colitis & 5 & $22(10-50)$ & $\begin{array}{l}\text { 5-aminosalicylates, } \\
\text { thiopurines, steroids }\end{array}$ & 0 & 1 & 4 & 0 & 0 & I \\
\hline Crohn's colitis & 3 & $19(|7-2|)$ & Steroids, thiopurines & I & 1 & I & I & 0 & I \\
\hline $\begin{array}{l}\text { Indeterminate } \\
\text { colitis }\end{array}$ & 4 & $19(|6-2|)$ & $\begin{array}{l}\text { Steroids, thiopurines, } \\
\text { 5-aminosalicylates }\end{array}$ & 3 & 0 & 1 & 3 & 0 & 0 \\
\hline $\begin{array}{l}\text { Collagenous } \\
\text { colitis }\end{array}$ & 2 & $15(12-17)$ & $\begin{array}{l}\text { Methotrexate, } \\
\text { loperamide }\end{array}$ & 2 & 0 & 0 & 0 & 0 & 2 \\
\hline $\begin{array}{l}\text { Lymphocytic } \\
\text { colitis }\end{array}$ & 1 & 24 & $\begin{array}{l}\text { Methotrexate, } \\
\text { loperamide, } \\
\text { gluten-free diet }\end{array}$ & I & 0 & 0 & 0 & 0 & I \\
\hline Chronic dIBS* & 4 & $50(23-104)$ & $\begin{array}{l}\text { Gluten-free and } \\
\text { other elimination } \\
\text { diets, antibiotics }\end{array}$ & 2 & 1 & 1 & 2 & 0 & 1 \\
\hline Total patients & 31 & $22(6-104)$ & & 16 & 7 & 8 & 10 & 2 & 11 \\
\hline
\end{tabular}

Notes: ++, good response; +, partial response; -_, nil response.

Abbreviation: dIBS, diarrheal irritable bowel syndrome.

increased to $240 \mathrm{mg}$ twice daily for 2 weeks; with a good response, patients continued after 1 month at either of these doses or at $120 \mathrm{mg}$ daily. Clinical assessments were collected at one month from commencement of CBS (initial response) and also at follow up in those who continued treatment for $\geq 1$ month.

We elected to dose bismuth orally in our patients not only because of the convenience of oral dosing but also because (i) the disease is not always accessible by enemas and (ii) oral bismuth, being poorly absorbed by the intestine, is mainly delivered to the colon. The initial decision to use colloidal bismuth subcitrate over another oral bismuth preparation, the subsalicylate form, was because the former is a single compound, whereas the latter is manufactured in combination with calcium carbonate. As salicylates per se can stimulate intestinal fluid and electrolyte absorption ${ }^{7,8}$ and calcium by itself possesses antidiarrheal and immunomodulatory properties, ${ }^{9,10}$ we chose to prescribe the subcitrate form of bismuth in our gastroenterology service.

Therapeutic responses were scored on the basis of number of liquid stools as recorded in the assessment module. The responses were classified as good, partial, or nil. A good response was defined as a bowel frequency of $\leq 3$ per day, with a decrease by at least 3 liquid stools per day from baseline. A partial response was defined as a reduction by $\geq 2$ liquid stools per day from baseline. Use of the database was approved by the Mater Hospital Human Research Ethics Committee.

\section{Results}

Thirty-one patients aged 17-79 years, mean age 47 years, with a mean duration of diarrhea of 22 weeks (range 6-104 weeks) were treated with CBS at doses ranging from $120 \mathrm{mg}$ to $480 \mathrm{mg}$ per day (Table 1). Twenty-three patients (74\%) had an initial clinical response. These patients were prescribed ongoing CBS. Twelve (39\%) of these patients had a documented sustained response at 1 year. The other eleven patients had stopped CBS therapy. Median total duration of daily CBS therapy in the eleven patients who had stopped was 13 weeks (range 7-42 weeks) (Figure 3). The twelve patients with pouchitis and four patients with indeterminate colitis had mainly good initial ( $92 \%$ and $75 \%$, respectively) and sustained (50\% and $75 \%$, respectively) responses, whereas five patients with ulcerative colitis responded poorly with respect to both initial $(20 \%)$ and a sustained response $(0 \%)$. All three patients with microscopic colitis showed an encouraging good initial response, but none of them had a sustained benefit at 1 year. The response to oral CBS in four patients with dIBS was encouraging, with three having had 
IBD Australian Clinical and Research Database (Mater Hospital)



Figure 2 Screen shot of the clinical assessment page from our web-based Inflammatory Bowel Disease (IBD) Clinical and Research Database. Note: Intractable diarrhea was defined as $\geq 4$ liquid stools/day.

an initial response and two having a good sustained response at 1 year.

All patients when taking CBS noted dark stools, which were well formed and easily distinguishable from melena. One patient complained of nausea, and one patient complained of abdominal pain. Blood biochemistry performed at 6-month intervals was unremarkable. No patients developed renal or neurological adverse events.

Six patients who had good clinical response to CBS continued using loperamide as and when required. Seven patients continued taking their usual medications for IBD. 




Figure 3 Kaplan-Meier plot of the proportion of patients on CBS over the 12 months. Abbreviation: $\mathrm{CBS}$, colloidal bismuth subcitrate.

\section{Discussion}

We report here a retrospective experience with oral CBS treatment for chronic intractable diarrhea. It includes all patients treated with CBS between 2000 and 2010 in our gastroenterology service. As far as we are aware, this is the largest reported series of oral CBS treatment for chronic diarrheal conditions. Chronic intractable diarrhea, which is not uncommon in gastroenterology and medical outpatient departments, is an important and challenging clinical problem for both treating physicians and patients. We found CBS to be an encouraging and safe symptomatic treatment for pouchitis, indeterminate colitis, and dIBS where other treatments had failed or were not adequate.

Owing to their well-known antidiarrheal properties, bismuth compounds have been commonly used to treat episodic diarrhea in children and adults for a century. ${ }^{11-14}$ Two studies have reported the efficacy of bismuth enema treatment for distal ulcerative colitis. An open-labeled study with patients resistant to conventional treatment showed a $60 \%$ clinical response rate and $40 \%$ complete remission rate after 8 weeks of therapy. ${ }^{15}$ A second multicenter, double-blind, randomized, control trial that compared bismuth enema with 5-aminosalicylic acid enemas showed an equivalent therapeutic benefit with bismuth enemas for the treatment of left-sided ulcerative colitis. ${ }^{16}$
Oral bismuth has also been used in microscopic colitis, ${ }^{17}$ as a colostomy deodorizer, and as an antispirochete agent in syphilis. ${ }^{18}$ There is a 4-week study from the Mayo clinic with oral bismuth salicylate for 13 patients with chronic antibioticresistant pouchitis. This showed a significant clinical benefit noted on follow-up at the end of 4 weeks. ${ }^{19}$

In addition to its antibacterial properties, ${ }^{6,18}$ bismuth is also thought to have anti-inflammatory effects. ${ }^{20}$ There are experimental data supporting a role inhibiting inducible nitric oxide synthase activity in intestinal epithelial cells and also to induce heme oxygenase-1, thereby imparting therapeutic effects against the inflammatory and oxidative stresses associated with inflammatory bowel disease. ${ }^{21}$ Another experimental study showed the ability of bismuth to scavenge oxygen-free radicals in the context of chemicalinduced gastric mucosal injury. ${ }^{22}$ Given these antibacterial and anti-inflammatory actions, it is theoretically feasible that bismuth should have a role in the treatment of acute and chronic diarrhea where bacteria and/or their toxins are implicated in the pathogenesis.

Hydrogen sulfide is a malodorous and toxic compound produced by colonic bacteria during the breakdown of protein. In moderately severe ulcerative colitis, ${ }^{23}$ hydrogen sulfide has been implicated in the inhibition of colonic mucosal butyrate oxidation, ${ }^{24,25}$ which can render the mucosa 
more vulnerable to inflammatory insults. Bismuth reacts with sulfide to produce insoluble bismuth sulfide, which colors the stool black but is innocuous. ${ }^{26}$

Bismuth is minimally absorbed and so has negligible potential for toxicity in patients with normal renal function. Any absorbed bismuth is mostly excreted in urine unless renal function is severely impaired. ${ }^{12,27}$ Toxicity from bismuth is rare unless ingested in extremely high doses ${ }^{28}$ (many times higher than the doses used by us). As CBS was swallowed whole, none of our patients experienced blackish discoloration of the tongue, teeth, or gums.

Despite the small number of subjects in this study, this represents the largest reported study to date with oral bismuth. Although this is not a prospective, randomized, controlled, drug trial, our observations suggest the possibility of substantial symptomatic benefit with the use of oral CBS in pouchitis, dIBS, and indeterminate colitis but not in ulcerative colitis. It is encouraging that at least in some patients, a sustained benefit was achieved. Although many of these disease entities are known to have spontaneous remissions and relapses, it seems unlikely that the unremitting diarrhea in some of our study patients lasting for months to years, despite being on standard treatment, would suddenly settle in its natural course when bismuth was initiated. We conclude that it would be worthwhile to conduct an appropriately powered, blinded, randomized, controlled study examining clinicopathological endpoints in defined groups of intractable diarrheal patients with pouchitis, dIBS, and indeterminate colitis.

\section{Disclosure}

The authors report no conflict of interest in this work.

\section{References}

1. Mallon P, McKay D, Kirk S, Gardiner K. Probiotics for induction of remission in ulcerative colitis. Cochrane Database Syst Rev. 2007:CD005573.

2. Siegel CA, Sands BE. Review article: practical management of inflammatory bowel disease patients taking immunomodulators. Aliment Pharmacol Ther. 2005;22:1-16.

3. Connell AM, Lennard-Jones JE, Misiewicz JJ, Baron JH, Jones FA. Comparison of Acetarsol and Prednisolone-21-Phosphate Suppositories in the Treatment of Idiopathic Proctitis. Lancet. 1965;1:238.

4. Forbes A, Britton TC, House IM, Gazzard BG. Safety and efficacy of acetarsol suppositories in unresponsive proctitis. Aliment Pharmacol Ther. 1989;3:553-556.

5. DuPont HL, Ericsson CD, Johnson PC, de la Cabada FJ. Use of bismuth subsalicylate for the prevention of travelers' diarrhea. Rev Infect Dis. 1990;12:S64-S67.

6. Sun H, Zhang L, Szeto KY. Bismuth in medicine. Met Ions Biol Syst. 2004;41:333-378.
7. Farris RK, Tapper EJ, Powell DW, Morris SM. Effect of aspirin on normal and cholera toxin-stimulated intestinal electrolyte transport. J Clin Invest. 1976;57:916-924.

8. Pickering LK, Feldman S, Ericsson CD, Cleary TG. Absorption of salicylate and bismuth from a bismuth subsalicylate-containing compound (Pepto-Bismol). J Pediatr. 1981;99:654-656.

9. Govers MJ, Termont DS, Van der Meer R. Mechanism of the antiproliferative effect of milk mineral and other calcium supplements on colonic epithelium. Cancer Res. 1994;54:95-100.

10. Govers MJ, Termont DS, Lapre JA, Kleibeuker JH, Vonk RJ, Van der Meer R. Calcium in milk products precipitates intestinal fatty acids and secondary bile acids and thus inhibits colonic cytotoxicity in humans. Cancer Res. 1996;56:3270-3275.

11. DuPont HL, Sullivan P, Pickering LK, Haynes G, Ackerman PB. Symptomatic treatment of diarrhea with bismuth subsalicylate among students attending a Mexican university. Gastroenterology. 1977;73: 715-718.

12. Bierer DW. Bismuth subsalicylate: history, chemistry, and safety. Rev Infect Dis. 1990;12:S3-S8.

13. Gryboski JD, Kocoshis S. Effect of bismuth subsalicylate on chronic diarrhea in childhood: a preliminary report. Rev Infect Dis. 1990;12: S36-S40.

14. Figueroa-Quintanilla D, Salazar-Lindo E, Sack RB, et al. A controlled trial of bismuth subsalicylate in infants with acute watery diarrheal disease. N Engl J Med. 1993;328:1653-1658.

15. Ryder SD, Walker RJ, Jones H, Rhodes JM. Rectal bismuth subsalicylate as therapy for ulcerative colitis. Aliment Pharmacol Ther. 1990;4: 333-338.

16. Pullan RD, Ganesh S, Mani V, et al. Comparison of bismuth citrate and 5-aminosalicylic acid enemas in distal ulcerative colitis: a controlled trial. Gut. 1993;34:676-679.

17. Fine KD, Lee EL. Efficacy of open-label bismuth subsalicylate for the treatment of microscopic colitis. Gastroenterology. 1998;114:29-36.

18. Degos R. Bismuth in the treatment of syphilis. Int J Dermatol. 1977; 16:391-392.

19. Tremaine WJ, Sandborn WJ, Kenan ML. Bismuth subsalicylate tablets for chronic antibiotic-resistant pouchitis. Gastroenterology. 1998; 114:A1101.

20. Ericsson CD, Tannenbaum C, Charles TT. Antisecretory and antiinflammatory properties of bismuth subsalicylate. Rev Infect Dis. 1990;12:S16-S20.

21. Cavicchi M, Gibbs L, Whittle BJ. Inhibition of inducible nitric oxide synthase in the human intestinal epithelial cell line, DLD-1, by the inducers of heme oxygenase 1, bismuth salts, heme, and nitric oxide donors. Gut. 2000;47:771-778.

22. Bagchi D, McGinn TR, Ye X, et al. Mechanism of gastroprotection by bismuth subsalicylate against chemically-induced oxidative injury in human gastric mucosal cells. Gastroenterology. 1998;114:A62.

23. Florin THJ, Gibson GR, Neale G, Cummings JH. A role for sulfate reducing bacteria in ulcerative colitis? Gastroenterology. 1990;98:A170.

24. Roediger WE. The colonic epithelium in ulcerative colitis: an energydeficiency disease? Lancet. 1980;2:712-715.

25. Chapman MA, Grahn MF, Boyle MA, Hutton M, Rogers J, Williams NS. Butyrate oxidation is impaired in the colonic mucosa of sufferers of quiescent ulcerative colitis. Gut. 1994;35:73-76.

26. Suarez FL, Furne JK, Springfield J, Levitt MD. Bismuth subsalicylate markedly decreases hydrogen sulfide release in the human colon. Gastroenterology. 1998;114:923-929.

27. Hasking GJ, Duggan JM. Encephalopathy from bismuth subsalicylate. Med J Aust. 1982;2:167.

28. Mendelowitz PC, Hoffman RS, Weber S. Bismuth absorption and myoclonic encephalopathy during bismuth subsalicylate therapy. Ann Intern Med. 1990;112:140-141. 
Clinical and Experimental Gastroenterology

Dovepress

\section{Publish your work in this journal}

Clinical and Experimental Gastroenterology is an international, peerreviewed, open access journal, publishing all aspects of gastroenterology in the clinic and laboratory, including: Pathology, pathophysiology of gastrointestinal disease; Investigation and treatment of gastointestinal disease; Pharmacology of drugs used in the alimentary tract;

Immunology/genetics/genomics related to gastrointestinal disease. This journal is indexed on CAS. The manuscript management system is completely online and includes a very quick and fair peer-review system. Visit http://www.dovepress.com/testimonials.php to read real quotes from published authors.

Submit your manuscript here: http://www.dovepress.com/clinical-and-experimental-gastroenterology-journal 